\title{
O ENSINO DA ANTROPOLOGIA NO BRASIL *
}

\author{
EUNICE RIBEIRO DURHAM E RUTH CORREA LEITE CARDOSO \\ (Universidade de São Paulo)
}

\section{INTRODUÇÃO}

O ensino da Antropologia, como o de qualquer disciplina, envolve sempre dois tipos de problemas: os de ordem didática, quer gerais, quer específicos à matéria, e os de organização dos cursos em têrmos da estrutura de ensino existente. Se os aspectos pròpriamente didáticos do ensino propõem questões gerais, que são as mesmas em todos os lugares, a organização do sistema escolar varia de país para país e propõe problemas particulares de adequação do ensino a condições diferentes de atuação do professor.

Para a compreensão dos problemas particulares do ensino da Antropologia no Brasil é necessário, portanto, uma análise preliminar do nosso sistema educacional, tanto nos seus aspectos estruturais quanto nas suas condições de funcionamento.

\section{1. ${ }^{a}$ PARTE}

Uma análise cuidadosa da situação brasileira encontra grandes dificuldades iniciais. Não possuímos dados precisos sequer sôbre o número de estabelecimentos onde se leciona Antropologia, e as indicações sôbre programas, número de alunos, qualificação de professôres, etc., são extremamente incompletas. Os dados que utilizamos foram obtidos através de um levantamento de instituições de ensino superior no Brasil onde são ministrados cursos de Antropologia. Aproveitamos bàsicamente as informações fornecidas pelo Centro Latino-Americano de Pesquisas Sociais para 1958, e completamos alguns aspectos recorrendo ao Ministério da Educação, às publicações da CAPES relativas ao ensino superior, e à Cadeira de Administração Escolar da Faculdade de Filosofia, Ciências e Letras da Universidade de São Paulo. Enviamos pedidos de informações a todos os estabelecimentos levantados, mas apenas 25 atenderam à nossa solicitação. Um número tão exíguo de respostas, evidentemente, apenas pôde servir para documentar a existência de alguns problemas mais gerais.

*) O presente artigo foi baseado em um relatório apresentado à V Reunião Brasileira de Antropologia, realizada em Belo Horizonte em junho de 1961. 
A julgar pelos dados puramente quantitativos, o ensino da Antropologia parece estar extremamente desenvolvido em nosso meio. Há pelo menos 54 estabelecimentos de ensino superior que lecionam a matéria. Estes dados são ainda mais significativos quando constatamos que, na Inglaterra, a Unesco aponta apenas sete universidades nas quais se ensina Antropologia, e na França apenas uma, além de quatro outros estabelecimentos de ensino superior ${ }^{1}$. Embora os dados da Unesco se refiram apenas ao ensino da Antropologia Cultural, o contraste não deixa de ser válido desde que, tanto na Europa quanto no Brasil, a Antropologia Física e a Antropologia Cultural são, em geral, lecionadas nas mesmas instituições.

O ensino da Antropologia no Brasil encontra-se realmente numa posição paradoxal. A hipertrofia do número de estabelecimentos que ministram cursos da matéria não está relacionada nem a possibilidades reais de formação de especialistas (sequer em número suficiente para satisfazer as necessidades didáticas) nem a condições satisfatórias de realização de pesquisas e aplicação do conhecimento antropológico.

Embora a grande maioria dos cursos de Antropologia no Brasil não se destine a formar antropólogos, mas a completar a formação de especialistas em outros campos, êles deveriam, através de uma iniciação na matéria, despertar vocações para a especialização na disciplina, que poderia ser realizada nas instituições aparelhadas para êste fim. Entretanto, dadas as condições de ensino e a própria estrutura universitária no Brasil, os cursos não produzem realmente os resultados que seriam possíveis e desejáveis .

No ensino superior a Antropologia é lecionada tanto no nível básico como no de pós-graduação e é parte integrante do currículo das Faculdades de Filosofia e das Escolas de Sociologia e Política. Como disciplina subsidiária, em caráter de formação de cultura geral, pode ser lecionada também nas Faculdades de Higiene e nas Escolas de Administraçấo de Emprêsas. Como parte de cursos de formação de pesquisadores, geralmente em nível pós-graduado, é ensinada ainda em diversas instituições de pesquisa, quer em cursos regulares, quer em cursos especiais e esporádicos. Fora do ensino universitário, é ainda ensinada, às vêzes, em cursos de extensão cultural. Examinaremos separadamente o ensino no nível superior básico e a formação de especialistas em nível de pós-graduação .

\section{Cursos em nível de graduação}

No nível do ensino superior básico, cabe às Faculdades de Filosofia a grande maioria dos cursos de Antropologia ministrados no Brasil e, portanto, as particularidades dêsse ensino prendem-se diretamente às características dessas instituições. Dessa vinculação decorrem duas ordens de 
fatôres: os que derivam das condições de funcionamento das Faculdades e os relacionados com a própria estrutura dos cursos.

Nos últimos 10 anos tem havido uma verdadeira proliferação de Faculdades de Filosofia. Seu número passa, no período entre 1949 e 1957 , de 22 estabelecimentos para um total de $52^{2}$. Contando a maioria delas com recursos muito precários, limitam-se a instalar apenas aquelas secções que exigem um mínimo de aparelhamento e que, representando quase que um curso de extensão cultural, podem atrair um número mais elevado de alunos: secções de Letras, Pedagogia, Geografia, História e, às vêzes, Ciências Sociais. Especialmente os cursos de Letras, Geografia e História são muito populares, porquanto, às vantagens apontadas acima, soma-se a facilidade de colocação no mercado de trabalho como professor secundário, em se tratando de matérias que são lecionadas em tôda a extensão do curso médio. Desta forma, é à exigência legal do ensino da Antropologia nas secções de Geografia e História que se deve o grande aumento do número de cursos de Antropologia no Brasil.

Em grande parte dessas instituições, a falta de recursos, a remuneração inadequada do corpo docente e o isolamento dos centros universitários que poderiam fornecer não só o estímulo para o aperfeiçoamento na disciplina como também possibilidades de remuneração suplementar, são fatôres responsáveis pelo caráter de improvisação que não raro assumem os cursos, pouco propícios a atrair pessoal qualificado. Ao mesmo tempo, a ausência de um equipamento material mínimo, inclusive de bibliotecas, o baixo nível de formação e aspiração dos alunos que procuram êstes estabelecimentos e a impossibilidade de seleção rigorosa em escolas que precisam de alunos para subsistir, contribuem para que o ensino seja elementar e insatisfatório. Da vinculação do ensino da Antropologia às Faculdades de Filosofia decorre a participação nessas condições precárias de realização dos cursos.

Por outro lado, desde que estas Faculdades se destinam à formação de professôres secundários, diminui de muito o interêsse dos alunos pela Antropologia, matéria que não tem aplicação imediata na sua vida profissional. Para isso contribui também a inadequação dos programas, desde que a falta de orientação de boa parte dos responsáveis pelo ensino da Antropologia dificulta uma organização da matéria de acôrdo com os interêsses centrais do curso.

Que apenas o melhor aparelhamento das escolas não viria sanar as deficiências do ensino da Antropologia prova-o o fato de que estas deficiências se manifestam também em instituições de mais recursos, pois derivam, em parte, da própria estruturação dos cursos das Faculdades de Filosofia. Na estrutura atual, a Antropologia é exigida apenas para as secções de Geografia, História e Ciências Sociais ${ }^{3}$. Nas secções de História e Geografia o ensino é ministrado em três anos, o que seria suficiente para uma visão geral da disciplina. Entretanto, a Antropologia ocupa, 
neste caso, uma posição nitidamente secundária no conjunto das matérias . Isto se deve não apenas à falta de entrosamento adequado, antes referido, como também à diferença da abordagem da Antropologia em confronto com as outras disciplinas do currículo, em geral de cunho mais informativo, o que contribui grandemente para a sensação, tanto da parte do aluno como da do professor, de tratar-se de uma matéria "marginal" aos interêsses do curso.

Quanto à secção de Ciências Sociais, a preparação dos alunos nas outras disciplinas do currículo favorece uma visão mais adequada dos problemas antropológicos e haveria, realmente, possibilidade de uma formação mais especializada em Antropologia, ou pelo menos em Antropologia Cultural. Entretanto, para Ciências Sociais as exigências legais limitamse apenas a um curso geral de Antropologia e Etnografia a ser ministrado na terceira série. O fato de a grande maioria das Faculdades que possuem também secções de Geografia e História estender para três anos o curso de Antropologia para Ciências Sociais não aumenta realmente as possibilidades de maior rendimento e melhor preparo dos alunos de Ciências Sociais, desde que os cursos são ministrados em conjunto para as três secções, e o tratamento da matéria é condicionado às limitações impostas pela organização dos cursos de Geografia e História.

Quanto à estruturação da matéria, de modo geral, a legislação prevê três cadeiras distintas no campo da Antropologia: Antropologia, Etnografia Geral (ou Etnologia) e Etnografia do Brasil, que deve incluir também Tupi-Guaraní. A própria designação das cadeiras está sujeita às mais diferentes interpretações. A cadeira de Antropologia pode ser interpretada ou como Antropologia Física, exclusivamente, ou como Antropologia Física e Cultural. A cadeira de Etnografia Geral pode ser simplesmente Etnografia (descrição de culturas), ou ser Etnologia no sentido de EvansPritchard, isto é, a escola Histórico-Cultural de Antropologia Cultural ou, ainda, Etnologia no seu sentido mais amplo, isto é, Antropologia Cultural. A cadeira menos sujeita a diversidade de interpretação é a de Etnografia do Brasil, a não ser quanto à inclusão, extremamente discutível, do Tupi como disciplina da cadeira. Essa ambigüidade da nomenclatura é em parte vantajosa, pois, pela sua flexibilidade, permite uma variação muito grande de programa, de modo a atender a interêsses específicos dos alunos. Possibilita, também, um aproveitamento maior do pessoal qualificado, em número exíguo, permitindo que o professor concentre a matéria nas áreas de sua especialidade. Por outro lado, não favorece uma integração dos diferentes cursos para uma visão ampla e unificada da matéria no conjunto. Para isso certamente contribui não só a separação das cadeiras como também a segregação de umas em relação às outras. E' verdade que, por vêzes, duas, ou mesmo tôdas as cadeiras são reunidas sob orientação de um único professor. Quando isso não ocorre, porém, as divergências na orientação dos professôres levam freqüentemente a repetições ou à omissão de 
questões essenciais e, inclusive, a atritos pessoais que prejudicam sobremianeira a organização racional do ensino.

Como consequiência dessa situação, os programas raramente abrangem o conjunto dos aspectos formalıntnte englobados pela disciplina. Deve-se mencionar inicialmente o abandono que se verifica em relação à Arqueologia, raramente incluída nos programas. Essa omissão é tanto mais grave quanto maior seria o interêsse dessa disciplina para alunos de História, que constituem boa parte dos estudantes de Antropologia.

Igualmente lamentável é a ausência de um curso de Lingüística, que apresentaria interêsse para um número muito grande de estudantes, como os de Letras e Filosofia. E' verdade que alguns professôres procuram dar elementos de Lingüística em substituição ou como introdução ao curso de Língua Tupi. Evidentemente, a própria organização da cadeira impede a sistematização dessas iniciativas. Não se justifica a inclusão da Língua Tupi, quer como disciplina da cadeira de Etnografia Brasileira, quer em qualquer outra forma que não como aspecto de um estudo geral de Linguística, ou, mais particularmente, de um estudo global de línguas indígenas brasileiras. De qualquer modo, estudos particulares e de interêsse restrito como êsse não têm lugar no curso universitário básico, em que a Antropologia não pode pretender mais que familiarizar os alunos com o tipo de investigação e a problemática característica da ciência. Por outro lado, não se justificaria também o estudo da Lingüística na cadeira de Etnografia Brasileira, dada a diferença de perspectivas e métodos entre as duas disciplinas .

Realmente, apenas a Faculdade de Filosofia da Universidade do $\mathrm{Pa}$ raná tem podido tentar superar essas deficiências, dada a organização departamental que a Antropologia assumiu nessa instituição. Como medida inicial para uma organização mínima do ensino e do rendimento do trabalho universitário seria essencial uma organização da Antropologia em departamentos, com uma divisão mais adequada dos diferentes campos. Essa organização, se mantida flexível de modo a atender a exigências variáveis, permitiria uma melhor divisão do trabalho entre especialistas e a organização mais coordenada dos diferentes aspectos da disciplina.

Nas outras instituições de ensino superior que não Faculdades de Filosofia, uma maior flexibilidade permite melhor adequação do ensino aos interêsses do curso. Dêsse ponto de vista, as Escolas de Sociologia estão em posição favorável, porquanto a ausência de regulamentação da matéria permite um desdobramento da Antropologia de modo mais racional. Na Escola de Sociologia e Política de São Paulo são oferecidos, regularmente, no curso básico, seis programas diferentes. Por outro lado, na Escola de Sociologia de Belo Horizonte, onde a Antropologia ocupa posição secundária, é oferecido apenas um curso de dois semestres, de introdução geral ${ }^{4}$.

No que diz respeito aos outros cursos no nível universitário básico, o problema é menos grave, porquanto, nesses cursos, como o que se ministra 
na Faculdade de Higiene de São Paulo e nos Cursos de Administração de Emprêsas, o ensino da Antropologia é extremamente elementar, visando apenas a completar a cultura geral dos estudantes.

Considerando o ensino da Antropologia Física no quadro geral do ensino universitário básico, manifesta-se imediatamente a limitação do ensino da Antropologia, tanto nas Faculdades de Filosofia como nas demais instituições, aos cursos de Ciências Sociais em geral.

A limitação aos cursos apontadas acima restringe sobremaneira as possibilidades do ensino da Antropologia Física, porquanto os alunos dêsses cursos não têm a necessária preparação nas ciências naturais, nem interêsse por êsse campo de estudo. Por outro lado, os cursos universitários que dão essa preparação não incluem a Antropologia em seu currículo. A Antropologia Física restringe-se, portanto, apenas a informações gerais e. quando muito, a uma caracterização dos problemas centrais da disciplina, que complementam uma formação voltada para as Ciências Sociais.

O ensino da Antropologia Cultural, embora encontre condições mais favoráveis, ressente-se da organização em cadeiras independentes, característica da maior parte das instituições onde se leciona a matéria, fazendo com que, com raras exceções, não se possa cobrir o âmbito das disciplinas nela formalmente englobadas.

\section{Cursos em nível de pós-graduação}

As possibilidades de especialização em Antropologia no Brasil restringem-se pràticamente à Antropologia Cultural. Em relação à Antropologia Física manifestam-se as mesmas deficiências apontadas para os cursos básicos. Não há, em primeiro lugar, alunos com suficiente formação para poderem iniciar uma especialização em Antropologia Física, de modo que nem sequer se apresenta a possibilidade de treinamento nessa disciplina através de bôlsas de estudos no estrangeiro. Correspondendo a essa falta de procura, não existem no Brasil cursos de especialização em Antropologia Física. O único curso de que tivemos conhecimento foi o promovido pelo Museu Nacional e pelo Instituto de Pesquisas Educacionais em 1957, e mesmo êsse não oferecia um treinamento sistemático na matéria. Como conseqüência dessa limitação, grande parte dos antropólogos físicos no Brasil são formados em medicina. Desde que o curso de medicina não oferece nenhuma base em Antropologia pròpriamente dita, a formação dêsses especialistas é necessàriamente autodidática e, muitas vêzes, insuficiente para fornecer uma visão realmente antropológica dos problemas .

Dentro da Antropologia Cultural, repetem-se, no nível de pós-graduação, as mesmas falhas do ensino superior básico. A Arqueologia e a Lingüística estão pràticamente esquecidas, apesar dos cursos já citados da Faculdade de Filosofia da Universidade do Paraná e da iniciativa cio $\mathrm{Mu}-$ seu Nacional no mesmo campo. 
Do mesmo modo que os cursos básicos, os cursos de especialização limitam-se, portanto, quase que só à Antropologia Cultural no seu sentido mais restrito, ou Etnologia. Ao que pudemos apurar, seis instituições oferecem, pelo menos esporàdicamente, cursos dêste teor: o Museu Nacional, as Faculdades de Filosofia de São Paulo, do Paraná e da Bahia e a Escola de Sociologia e Política de São Paulo. Dessas, a que realmente proporciona uma formação mais completa, incluindo um treinamento em pesquisas de campo e, principalmente, em pesquisas de equipe, é o Museu Nacional. A Escola de Sociologia e a Faculdade de Filosofia de São Paulo também promovem atividades de pesquisa. A primeira destas, especialmente, oferece um grande número de cursos pós-graduados, dando bastante importância à pesquisa de campo. Nenhuma dessas instituições, entretanto, pode programar o trabalho de preparação sistemática e orientação no campo que o Museu Nacional proporciona aos seus estudantes. Cumpre mencionar ainda, entre as iniciativas no ensino pós-graduado, os cursos iniciados por Darcy Ribeiro no $\mathrm{Mu}$ seu do Índio, que lançaram as bases para o curso atual do Museu Nacional. E, entre as iniciativas de instituições para formação de um corpo de pesquisadores próprios, o curso realizado no Centro Brasileiro de Pesquisas Educacionais.

Analisando as condições em que o ensino da Antropologia se está realizando, vemos que as perspectivas para cursos pós-graduados são realmente muito limitadas. Mesmo entre as seis escolas que contam com cursos pós-graduados e têm como objetivo formar pesquisadores, algumas não contam com possibilidades materiais de fornecer uma especialização, conforme depoimento de seus professôres. Algumas das respostas que recebemos foram análises muito sugestivas do curso de Antropologia, e das decepções sucessivas de professôres dedicados e competentes que não conseguem fazer funcionar cursos mais avançados. As poucas oportunidades de trabalho limitam o número de alunos interessados e a formação ampla que se exige do antropólogo torna de alto custo qualquer iniciativa neste sentido, dificultando extremamente sua realização.

\section{A qualificação do corpo docente}

Desde que a Antropologia é ensinada quase que exclusivamente no Ensino Superior, onde não cabe uma distinção entre professôres de Antropologia e antropólogos, as deficiências da formação especializada em Antropologia refletem-se necessàriamente no ensino da matéria, muitas vêzes ministrado por pessoas sem nenhuma qualificação específica. E' verdade que, ainda hoje, os nossos melhores antropólogos, são, em maior ou menor grau, autodidatas. Entretanto, a suficiência e, às vêzes, eminência no campo através da formação autodidática requer capacidade e dedicação, que não são características de todos. Com a necessidade de um número 
cada vez maior de professôres de Antropologia, é necessário, cada vez mais, que se exija uma preparação específica na disciplina, quer através de cursos especializados, quer da comprovação de uma capacidade real do autodidata, que pode ser avaliada pelas obras publicadas.

Entre as escolas superiores que responderam ao nosso questionário apenas sete têm licenciados em Ciências Sociais ou formados em Sociologia e Política respondendo por cadeiras; em outras dezoito cadeiras estão ou professôres formados por cursos de Geografia ou História, onde se dá Antropologia ( cinco casos), ou cursos considerados afins à matéria Medicina ou História Natural (doze casos); há ainda um professor que não indicou qualquer título de escola superior.

Não estamos pretendendo que êstes vinte e cinco casos representem exatamente a situação no Brasil, mas êles são suficientes para demonstrar que muitas cadeiras são entregues a pessoas sem formação especial em Antropologia. E isto se infere não porque sua formação universitária básica seja heterogênea, mas principalmente porque muitos dêsses professôres não têm qualquer trabalho publicado no campo, e pouquíssimos citam cursos de pós-graduação. Se tais cursos tivessem sido procurados, teriam dado a formação necessária, mesmo com a grande variação de cursos básicos. Só treze dêsses docentes têm algum trabalho publicado, e três outros, apesar de não apresentarem publicações, têm cursos de pós-graduação. Quando se pensa em cursos de pós-graduação, é ainda mais séria esta falta de pessoal habilitado, pois neste caso é condição primeira e fundamental a existência de um professor com formação rigorosa de profissional. Muito poucas instituições contam com corpo docente que, qualitativa e quantitativamente, possa desincumbir-se de obrigações tão absorventes .

O sucesso de cursos de Antropologia depende não só da existência de alguns professôres capazes, mas também de apoio e recursos que difìcilmente existem com continuidade. Tais recursos são muito escassos, como vimos pelas vinte e cinco escolas que nos responderam, onde constatamos serem muito raros os assistentes (dez escolas). Quando existem, freqüentemente se encarregam de uma disciplina dentro da Antropologia, fazendo, portanto, o trabalho que corresponderia a outro professor, em lugar de compor uma equipe onde se dividam trabalhos didáticos, de assistência aos alunos e de pesquisa.

Grande parte dos problemas aqui apontados são, evidentemente, decorrência natural da imaturidade do desenvolvimento científico entre nós, que somos ainda, também nêste campo, um país subdesenvolvido. Certamente é encorajador o número de iniciativas para a extensão do ensino superior, quer público quer privado, bem como o interêsse crescente pela realização de pesquisas científicas que tem motivado a criação de tantos novos institutos. 
A Antropologia tem se beneficiado dessas iniciativas. Entretanto, o reconhecimento das deficiências deve levar a um esfôrço positivo de melhoria, e, principalmente, de criar condições que evitem a perpetuação da situação vigente.

\section{2. ${ }^{a}$ PARTE}

Passaremos agora a uma outra ordem de considerações ligadas à tarefa de ensinar Antropologia. O professor, ao ensinar uma disciplina, enfrenta sempre dificuldades decorrentes da própria natureza da matéria. A escolha dos problemas a serem ressaltados e das qualidades que devem ser estimuladas nos trabalhos dos alunos são decisões que o professor deve tomar a partir de um exame geral dos conhecimentos que lhe cabe transmitir e da abordagem específica da ciência.

Tentaremos discutir o ensino da Antropologia dêsse ponto de vista, isto é, partindo de seus aspectos distintivos para chegar às condições necessárias ao seu sucesso. Discutindo separadamente os dois níveis de ensino, trataremos em primeiro lugar dos cursos de graduação, onde se manifestam os problemas de todos os cursos básicos de Antropologia; e, a seguir, apresentando as condições para a formação do antropólogo profissional, procuraremos analisar os problemas especiais dos cursos de pósgraduação .

\section{Cursos em nível de graduação}

A natureza da Antropologia exige uma formação básica bastante ampla. Não é necessário retomar as discussões acêrca do objeto desta ciência para reconhecer que ela se define numa área de integração dos conhecimentos sôbre o homem, valendo-se de recursos da ciência e das humanidades, para encontrar uma perspectiva especial de encarar a multiplicidade dos aspectos caracterìsticamente humanos.

Por necessidade inerente a esta situação, a Antropologia maneja recursos (técnicas e conceitos de diferentes procedências) que devem se integrar num todo único de conhecimentos.

$\mathrm{Na}$ realização dessa tarefa pressupõe-se conhecimentos extensos, mas não só erudição. A importância da formação universitária está justamente em permitir êste avanço além da erudição, tornando criador o acúmulo de conhecimentos. O ensino da Antropologia nas Universidades deve enquadrar-se num currículo que promova essa atitude criadora.

Não cremos que ensinar Antropologia seja simplesmente descrever povos primitivos ou raças humanas. Existe uma abordagem que caracteriza o trabalho antropológico e é isso que é importante transmitir aos alunos. A comunicação dos resultados obtidos no trabalho científico é, para o pro- 
fessor, uma oportunidade de mostrar como se chegou a tais conclusões e porque elas foram procuradas.

Os programas de formação básica que se limitam a apresentar particularidades de povos primitivos perpetuam a visão da Antropologia como uma atividade de excêntricos, colecionadores de raridades e' de notícias mais ou menos espantosas acêrca de povos estranhos. E' verdade que um programa dêsse tipo pode dar ao aluno uma compreensão da diversidade das culturas humanas e desenvolver uma atitude simpática com relação aos povos primitivos, permitindo mesmo uma certa comunicação através das barreiras culturais. Esta é uma condição para se fazer Antropologia, mas não é suficiente. Embora a visão totalizadora que a Antropologia procura decorra desta possibilidade de conhecer e respeitar o humano em suas formas diversas, é preciso ir além da descrição do exótico para explicar, através de cada situação estudada, os problemas que estão sendo propostos pela ciência .

Lévi-Strauss, em seu trabalho sôbre o ensino da Antropologia Cultural, editado pela Unesco ${ }^{5}$, ressalta a inutilidade dêste tipo de programas: "A Antropologia tornou-se uma disciplina muito diversificada e muito técnica para que se possam recomendar cursos que se limitam a um ano, e geralmente intitulados "Introdução à Antropologia" (ou outra fórmula do mesmo gênero) e que consistem habitualmente em vagos comentários sôbre a organização clânica, a poligamia e o totemismo. E' especialmente perigoso supor que, com tais noções superficiais, se pode dar qualquer preparação aos jovens (pág. 123).

E' absolutamente necessário que os cursos iniciais de Antropologia contribuam para a formação de uma atitude científica, pondo em evidência as principais orientações desta ciência no momento atual, e dando ao aluno um mínimo de instrumentos de trabalho, isto é, conceitos fundamentais, que devem ser manejados com relativa desenvoltura.

E' preciso justamente que através dos itens escolhidos para programa, o aluno tenha uma visão da diversidade de abordagens que a Antropologia permite, e também seja capaz de perceber as limitações destas perspectivas. Para isso, é imprescindível que o professor não se furte a uma preocupação constante de atualização de seus conhecimentos. Não é admissível que um programa de Antropologia não apresente pelo menos a abordagem funcionalista ou outras que preocupam atualmente os investigadores. A apresentação das escolas ou métodos, segundo uma sequiência histórica, é interessante, mas desde que chegue até aquelas orientações que atualmente estão preocupando os especialistas.

O caráter integrativo do conhecimento antropológico obriga o professor de um curso de Introdução a abordar temas muito diferentes. A primeira diferenciação é imposta pela dualidade fundamental desta ciência, que conjuga fenômenos biológicos e culturais em seu campo. Isto, porém, em lugar de ser uma limitação é uma vantagem, porque justa- 
mente nas conexões existentes entre assuntos tão diversos é que o aluno encontrará a perspectiva antropológica. Nenhuma sequiência didática justifica o isolamento de subcampos da Antropologia neste nível de ensino introdutório. O objetivo da iniciação é justamente definir uma perspectiva e fazer o aluno descortinar os caminhos apontados por êste conhecimento. Daí a necessidade de apresentar as hipóteses gerais de ambos os campos da Antropologia, reunindo e integrando os problemas que sempre preocuparam os especialistas e esclarecendo principalmente o sigvificado daquelas hipóteses para a compreensão do homem. Tal atitude permite aos alunos compreender o valor explicativo dêstes conhecimentos e não aceitá-los simplesmente a partir das oportunidades para sua aplicação. Não se deveria justificar um curso de Antropologia pelos setores em que ela pode ser aplicada, mas sim a partir da totalidade de conhecimentos que permite e dos problemas humanos que propõe.

Evidentemente não somos contrários à Antropologia Aplicada, apenas não é legítimo (especialmente no Brasil) apresentar ao aluno uma preocupação intelectual como válida só na medida em que pode ser imediatamente utilizada, mesmo quando ela possa se definir através de sua aplicabilidade. No Brasil, onde as oportunidades de aproveitamento de antropólogos são tão restritas, seria um êrro proclamar a Antropologia como uma ciência que pode ser utilizada na indústria, nos planejamentos regionais, etc. porquanto, a inexistência destas oportunidades levaria a defini-la como um conhecimento acessório e dispensável. Mais importante é construir uma atitude de curiosidade intelectual (através das hipóteses gerais da ciência), e apresentar os recursos necessários (técnicas científicas rigorosas) para tratar os problemas humanos, enriquecendo sempre êste conhecimento através das perspectivas de atuação. A Antropologia se apre. sentaria como um conjunto de problemas e instrumentos cuja significação está na possibilidade de uma compreensão adequada e geral do homem que não se distingue da ação, porque a permite.

Dando esta feição aos cursos de Introdução, estamos tentando ressaltar certos aspectos específicos da Antropologia, que devem estar sempre presentes nêste nível de ensino. Considerando que os cursos de História e de Geografia são em muito maior número que os outros onde se ensina Antropologia, cabe uma recomendação especial para que os professôres dêsses cursos atendam, na organização dos programas, aos interêsses principais de seus alunos. E' inegável que se deve procurar indicar os pontos de contacto da Antropologia com outras especialidades, sem transformá-la, porém, num apêndice da Geografia Humana ou da História Geral. Realizando um programa especificamente antropológico, podem-se ressaltar aquêles aspectos que enriquecem a perspectiva de disciplinas afins.

E' razoável que, num curso para futuros historiadores ou professôres de História, se sublinhem os temas ligados à reconstrução de culturas e ao valor dêste método; ou ainda, que se indique o ângulo por que se podem 
abordar os problemas de mudança cultural tendo em vista as linhas gerais da transformação de áreas culturais .

Com os alunos de Geografia, seria interessante discutir o conceito de área cultural e sua utilidade, além de apresentar a interação do homem com o ambiente, quer através da cultura, quer através do processo biológico da adaptação.

O que se espera pois, é que ao ensinar Antropologia nestes cursos, ao lado de apresentar o ponto de vista característico desta ciência, se escolha sempre uma maneira de abordar problemas que permita certas inferências que, sem o auxílio do professor, só estariam ao alcance dos alunos mais maduros e informados, capazes de perceber interrelações entre conhecimentos diversos.

\section{Cursos em nível de pós-graduação}

A formação de profissionais inicia-se com o curso introdutório, mas ganha importância justamente no nível de pós-graduação, quando a especialização realmente tem início. A necessidade de uma formação ampla, que já foi ressaltada, deve ser encarada não apenas com relação às diferentes especialidades dentro da Antropologia, mas, principalmente, com relação a matérias afins de grande importância para a formação de um antropólogo. Como já foi apontado anteriormente, a ausência da Antropologia nos cursos voltados para as ciências naturais pràticamente limita as possibilidades de especialização à Antropologia Cultural. E dado que não existe (e não existem condições para que venha a existir no Brasil) um curso universitário de Antropologia, é do curso de Ciências Sociais que, teòricamente, devem sair os candidatos a uma especialização em Antropologia. Evidentemente, uma formação básica englobando diferentes ciências sociais é da máxima importância, porque pode dar certa segurança com relação aos problemas metodológicos comuns a elas. A especialização posterior, em qualquer campo da Antropologia, se fará aproveitando êste "background", e completando-o com disciplinas necessárias, mas distantes das ciências sociais.

Os outros cursos de cujos currículos faz parte a matéria têm em vista a formação de historiadores, geógrafos ou psicólogos e seu ensino é justificado como matéria subsidiária nestas especialidades. E' claro que não se pode negar a possibilidade de alunos dêstes cursos virem a se especializar em Antropologia, mas é evidente que trazem uma bagagem menor de conhecimentos úteis para trabalhar neste campo.

Mesmo os alunos de cursos de Ciências Sociais têm que se preocupar com um alargamento de seus interêsses de estudo procurando um contacto, ainda que superficial, quer com as ciências biológicas e naturais, quer com as humanidades, que the vão oferecer justamente um mo- 
dêlo de conhecimento totalizador, e formar seu espírito para um certo tipo de apreensão da realidade indispensável ao antropólogo ${ }^{6}$.

São, pois, condições para uma especialização em Antropologia em nível de pós-graduação: $1^{\circ}$ ) a ampliação de conhecimentos dentro e além co campo desta ciência, e $2 .^{\circ}$ ) a participação em um trabalho que permita ao aluno conhecer e realizar tôdas as fases de uma pesquisa.

Realmente, só se pode considerar eficiente um curso pós-graduado quando a avaliação do rendimento é feita em têrmos de um trabalho realizado que qualifique o candidato como profissional. Evidentemente, tal trabalho contará com a assistência do professor responsável, mas, ao mesmo tempo, será o primeiro teste por que passa o talento criador do futuro especialista. Realmente, quer para os futuros professôres, quer para os futuros pesquisadores, a realização de uma pesquisa é muito importante para a qualificação de um profissional, e esta deve ser a preocupação dos orientadores dos respectivos cursos.

Através da participação na coleta e interpretação de dados é que o aluno pode ser treinado em certas "habilidades" que deve adquirir para fazer Antropologia. Margaret $\mathrm{Mead}$, em um artigo sôbre o treinamento de antropólogos culturais ", indica algumas dessas "habilidades": 1. ${ }^{\circ}$ ) $\mathrm{Ca}$ pacidade de levantar hipóteses de trabalho e prever as situações teóricas que deverão ser enfrentadas sôbre a base de fontes primárias e informações parciais e incompletas fornecidas por viajantes ou missionários. E' necessário, pois, familiarizar o aluno com as técnicas de pesquisa bibliográfica, fazendo com que perceba a sua utilidade como auxiliar do trabalho de campo, 2.0) Capacidade de reconhecer um "padrão". O conhecimento global que pretende a Antropologia pode ser favorecido, pondo-se o aluno em contacto com realidades mais ou menos simples, onde seja mais fácil a apreensão da totalidade. O trabalho de campo permite êste contacto, que, entretanto, deve ser antecedido por um treinamento baseado em leituras. 3. ${ }^{\circ}$ Familiaridade com populações de culturas diferentes, obrigando a uma atitude analítica e objetiva, concorde com as noções elementares já adquiridas. 4. ${ }^{\circ}$ ) Objetividade e capacidade de observação.

Em resumo: as aptidões necessárias a um bom profissional podem ser adquiridas no campo, pelo exercício destas mesmas aptidões, tal como no ensino médico, em que a prática do diagnóstico é que capacita o estudante a diagnosticar.

Segundo a autora citada, porém, tal prática pode e deve ser realizada pelo aluno individualmente, sem nenhuma assistência direta. Não parece ser esta a opinião mais aceita e nos colocamos entre aquêles que pressupõe a direção de um professor para que uma pesquisa seja realmente uma atividade formadora. Entre nós, os resultados de um curso de pós-graduação mantido pelo Museu Nacional confirmam esta afirmação.

Porém, é preciso distinguir dois tipos de trabalhos que são exigidos em cursos de aperfeiçoamento: algumas vêzes o aluno é apenas um auxi- 
liar do professor e realiza para êles as tarefas mais desagradáveis ou mais simples, sem participar realmente da proposição do problema ou da elaboração do trabalho. Mesmo esta maneira de colaborar em uma pesquisa traz algumas vantagens para o aluno, permitindo-lhe uma certa familiaridade com situações de trabalho de campo, mas, na verdade, pensamos em trabalho dirigido em outros têrmos. A pesquisa deve ser proposta já de forma didática, para que o aluno possa colaborar em todos os estágios, recebendo para isto o estímulo e orientação do professor que, no caso, não será um mero controlador de tarefas.

Esta maneira de trabalhar é possível, mesmo quando se trata de colaboração em uma pesquisa de interêsses do professor, o que, aliás, deve ser a situação normal. Há sempre áreas de trabalho que interessam ao professor enquanto pesquisador, e nessas áreas deve se situar o trabalho coletivo, porque aí é que sua orientação pode ser eficiente uma vez que existe um conhecimento anterior que facilita o planejamento e impõe maior rigor e segurança ao desenrolar da pesquisa. E', porém, absolutamente imprescindível que, como resultado do trabalho coletivo, cada participante elabore alguns aspectos do material colhido, objetivando o que houve de fecundo na experiência, e oferecendo oportunidade para que se avalie a capacidade de transpor a realidade em têrmos antropológicos.

Tal forma de trabalho coletivo e dirigido se impõe atualmente como uma necessidade da formação de pesquisadores sociais, porque o trabalho de equipe é uma decorrência do tipo dos problemas propostos para pesquisa, do interêsse por sociedades maiores e mais complexas e da incorporação de técnicas mais rigorosas de trabalho. Esta organização de trabalho já tem mostrado sua eficiência, especialmente nos campos em que tem lugar a pesquisa interdisciplinar. No âmbito da Antropologia são freqüentes as áreas que podem e têm sido abordadas dessa maneira. Tanto os professôres quanto os alunos devem se ajustar a êste tipo de trabalho, e a pesquisa dirigida seria uma excelente oportunidade para isto, porque permitiria aos jovens incorporar uma experiência fundamentai por ser completa.

E' necessário agora examinar quais as condições necessárias para que se possa realizar um ensino dêste padrão.

As dificuldades para se construir um corpo docente diversificado e eficiente já foram apontadas, e não é necessário encarecer mais o papel fundamental que tem o professor com formação rigorosa, especialmente para os cursos de pós-graduação.

O trabalho de campo, que é fundamental para a formação do antropólogo, exige uma direção firme, mas também verbas e outros recursos materiais inexistentes, como bibliotecas. Não há uma estrutura universitária capaz de sustentar o empenho de alguns poucos especialistas que, por isso mesmo, têm apenas alguns alunos, felizmente os mais devotados à matéria. 
E' recomendável que o ensino em nível de pós-graduação se restrinja apenas a algumas instituições, desde que um entrosamento adequado entre os diferentes cursos existentes permita aproveitar alunos de diversas procedências. Uma política correta de aplicação dos recursos des-.tinados ao aperfeiçoamento de pessoal qualificado tornaria os cursos mais eficientes e as verbas melhor aproveitadas.

E' reivindicação de qualquer escola que pretenda uma real formação de pesquisadores o tempo integral para alunos e professôres, e os recursos necessários para manter bôlsas e suprir despesas de pesquisa. Nossa experiência na Faculdade de Filosofia de São Paulo, onde para o curso de especialização é exigência fundamental a apresentação de un trabalho original, mostra que poucos alunos conseguem levar avante o curso porque, tendo outras obrigações profissionais. não dispõem de tempo para a pesquisa. Mesmo nos cursos de bacharelado (4. ${ }^{\circ}$ ano) êste problema já se coloca, pois o programa de leituras é mais extenso e a falta de livros e revistas disponíveis dificulta bastante o estudo. Seria necessário, pois, profissionalizar o aluno já no curso pós-graduado, dando-lhe tarefas de pesquisa e permitindo aquela dedicação necessária ao amplo programa que deve percorrer o aprendiz até conseguir uma experiência realmente integradora. Defendendo a necessidade de os alunos realizarem trabalho de campo, diz Lévi-Strauss que "é por uma razão muito profunda, que se liga à natureza mesma da disciplina e ao caráter distintivo de seu objeto que o antropólogo tem necessidade de experiência de campo. Para êle, esta não é nem uma finalidade de sua profissão, nem um aprimoramento de sua cultura, nem um aprendizado técnico. Representa um momento crucial de sua educação" 8 . Êste momento crucial só é possível com a plena dedicação que se deve proporcionar a alunos e professôres.

\section{Conclusões}

Em conclusão, gostaríamos de salientar algumas das dificuldades mais prementes do ensino da Antropologia no Brasil.

Não se pode deixar de lado o problema das bibliotecas, que precisam ser aparelhadas para servir aos estudantes. Devem estar atualizadas e contar com obras fundamentais em número suficiente. E' ainda LéviStrauss que insiste na importância da leitura de milhares de páginas de monografias antropológicas através das quais o estudante pode reviver uma experiência de campo $^{9}$. Poucas são as bibliotecas que podem atender a essa necessidade, e, entretanto, é uma condição indispensável para o sucesso de um curso.

Levando em conta a situação educacional brasileira, seria interessante que se promovesse a tradução de obras fundamentais, formando uma pequena biblioteca antropológica em língua portuguêsa que pudesse ser adqui- 
rida e usada em tôdas as Faculdades, permitindo assim que todos os cursos de graduação pudessem ser acompanhados com leituras fundamentais.

E' preciso apontar ainda a necessidade de um corpo docente realmente qualificado, o que deveria ser promovido pelo estabelecimento de exigências mínimas para o exercício do magistério superior. O melhor aparelhamento das instituições que ministram cursos de especialização, e a existência de um sistema eficiente de bôlsas de estudos seria suficiente para a formação do pessoal necessário .

Passando para o nível da organização da nossa universidade, deparamos com outros tantos obstáculos ao desenvolvimento de um trabalho produtivo de pesquisas conjugado ao trabalho didático. Para as cadeiras de Antropologia esta limitação se torna maior, uma vez que, por características da própria disciplina, há várias especializações possíveis dentro de seu campo e se torna necessária a colaboração de vários profissionais, para que se possa levar avante pesquisas de tôdas as disciplinas que aí estão englobadas.

Seria preciso uma organização mais maleável, que permitisse o entrosamento dessas várias especialidades em um trabalho comum, e onde o próprio trabalho didático pudesse ser enriquecido em colaboração mais ampla. O trabalho de equipe, necessário não só para a formação do aluno, mas como requisito das pesquisas modernas, só é possível em tais condições, e quase nunca pode ser feito em cadeiras onde o trabalho didático é absorvente, o número de pessoas insuficiente e onde, quando existe a colaboração de diversos especialistas, cada qual dá o seu curso mais ou menos independente, sem nenhuma colaboração no trabalho.

A formação de Departamentos de Antropologia permitiria talvez um maior entrosamento, criando no plano didático uma possibilidade de entendimento entre os vários professôres, e possibilitando no plano da pesquisa a colaboração entre os diversos especialistas.

Para aquelas instituições que oferecem cursos de pós-graduação, esta colaboração é fundamental, e por isso mesmo tais departamentos devem poder diversificar seu pessoal o suficiente para englobar arqueólogos, antropólogos físicos, lingüísticos, etc., formando uma verdadeira equipe capaz de realizar um trabalho didático de alto nível e pesquisas de um bom padrão. Alunos bolsistas do curso de pós-graduação trabalhariam junto ao Departamento, sob a orientação de especialistas diversos. A Antropologia seria, então, apresentada aos alunos realmente como uma síntese de perspectivas, atualizadas constantemente pelo exercício de um trabalho criador.

Indo tão longe em nossa tarefa de apontar os pontos fracos e algumas soluções para os cursos de Antropologia em nível de pós-graduação, pode parecer que nos esquecemos de considerar o esfôrço realizado em algumas escolas para atingir a um melhor nível de ensino. Pelo contrário, foi a partir dessas tentativas e da observação das frustações su- 
cessivas dos professôres que procuramos examinar em todos os níveis os obstáculos que devem ser afastados para que se consiga, realmente, formar um antropólogo.

\section{NOTAS}

1) UNESCO: Les Sciences Sociales dans l'Enseignement Supérieur - Sociologie. Psychologie Sociale et Anthropologie Culturelle. UNESCO, Paris, 1954, pág. 33.

2) Boletim Informativo da Campanha Nacional de Aperfeiçoamento do Pessoal de Nivel Superior, n. ${ }^{\circ}$ 14, janeiro 1951; e CAPES: Estabelecimentos de Ensino Superior, Série Informativa, Rio de Janeiro, 1958.

3) Na Faculdade de Filosofia da Universidade de São Paulo, há também um curso de Antropologia, de um ano, para os alunos da secção de Psicologia.

4) Não pudemos obter informações sôbre a escola de Pernambuco.

5) UNESCO, op. cit.

6) Redfield, R.: "Relations of Anthropology to Social Sciences and to Humanities", in Kroeber, A. L. (ed.): Anthropology Today, The University of Chicago Press, Chicago, 1953.

7) Mead, Margaret: "The Training of the Cultural Anthropologist", in American Anthropologist, vol. 54, n. ${ }^{\circ}$ 3, 1952, págs. 344 e segs.

8) UNESCO, op. cit., pág. 126.

9) UNESCO, op. cit., pág. 123. 